\title{
COVID-19 Pandemic - A Review and Assessing Higher Education Institution Undergraduate Student's Mental Health
}

\author{
Mohd Amiruddin Mohd Kassim ${ }^{1}$, Nicholas Tze Ping Pang ${ }^{1, *}$, Sandi James ${ }^{1,2}$
}

\section{Abstract}

Introduction: The current COVID-19 pandemic has sequelae reverberating around Malaysia, particularly in university students, as Malaysian university students are isolated in their university campuses in semi-quarantine status. This article seeks to review the existing literature on the specialized issue of university student-related psychological sequelae of COVID-19, and seeks to offer some recommendations through the process.

Methods: Existing literature demonstrates that COVID-19 has affected university students psychosocially, with the rate of anxiety and depression markedly increased. There have been significant alterations of lifestyle related to education, in accordance with the new normal, resulting in isolation and feelings of disengagement with education. Moreover, with the current uncertainties regarding their studies and possible financial depression postpandemic, the future is deeply worrying and will adversely affect their mental health.

Results: Quantitatively, recent findings indicate $33.3 \%$ of the undergraduates in a higher education institution are noted to be in stress. Therefore, multiple interventions have been implemented; a customized ultra-brief psychological module, an online tele psychiatry hotline (COVID Cares) and tele-counselling, which have received universally positive feedback.

Conclusion: In conclusion, the review demonstrates that undergraduates' psychological health is an aspect that needs urgent attention as it is not merely limited to the fear of COVID-19, but also related to the social aspects of the pandemic. Multiple interventions have been seen to be efficacious in reducing the psychological sequelae.

Keywords: Undergraduate; Mental health; COVID-19; Education

Correspondence Email: nicholas@ums.edu.my

${ }^{1}$ Faculty of Medicine and Health Science, Universiti Malaysia Sabah, Malaysia

${ }^{2}$ Department of Social Work and Social Policy, School of Science, Health and Engineering, La Trobe University, Australia

Received: $12 / 05 / 2020$

Accepted: 25/11/2020 


\section{Introduction}

Numerous articles have been written about the impact of the current COVID-19 pandemic on the mental health and wellbeing of the general population and front-line staff working in health care settings (Greenberg, N., et. al., 2020; Kang, L., et. al., 2020). However, little has been specifically focused on the impact of this crisis on undergraduate students trying to negotiate a whole new way of learning, the lack of social contact with peers and teachers, and managing to maintain their studies while potentially living in less than ideal situations. Hence, this is an especially vital aspect to explore, as the age of prevalence of mental health issues is predominantly in the early twenties, namely the same age as undergraduates.

While coronavirus disease 2019 (COVID-19) continues to spread around the world, many countries have decided to close educational institution as part of a policy to slow transmission and ease the burden on health systems (Van, L.W. et. al., 2020). Up until $9^{\text {th }}$ May 2020, The UN Educational, Scientific and Cultural Organization (UNESCO) estimates that 177 countries have closed schools and universities nationwide, and several other countries have implemented regional or local closures (UNESCO-IIEP, 2020). The situation in Malaysia is a peculiar one, in which many students are isolated in on campus accommodation and restricted to movements only within the university compound. This can cause a lot of behavioural consequences, including stigma, anxiety, and self-stigma (Koh, E.B.Y. et. al., 2020).

\section{Methodology}

This paper was structured as a perspective from the authors, rather than aiming to be an overarching attempt to perform a systematic review of the existing literature. Papers that were related to the current situation and the impact on the mental health and wellbeing of undergraduate university students were reviewed and the various viewpoints synthesised in a perspective article. A literature search was performed in Google Scholar, Embase and PsychINFO to highlight papers that were focused on the effects of COVID-19 in undergraduate university students. The panel of authors then chose certain papers that were more relevant to the perspective of undergraduate students, be it from an aetiology, psychopathology, or intervention point of view. As this was not an original paper or a meta-analysis, statistical tests were not performed as part of the methodology of the paper, and there are no original results to report in this paper. Due to the paucity of literature focusing on undergraduate students in COVID-19 and the time pressures, the grey literature or postgraduate theses were unable to be searched, as the pandemic has only been present for an insufficient duration to allow a Master's thesis to have been completed. 


\section{Results}

\section{Psychosocial Impact on Undergraduate Students}

There is ongoing uncertainty about how long the coronavirus crisis will last and how it affects the short and long-term mental health of students and staff across the world's educational institutions. The psychological impact is markedly significant, with increasing anxiety and uncertainty, increased stress, and fear and sadness about the future. Current research strongly suggests that rates of anxiety and depression with increase dramatically, exacerbated by uncertainties and the intensive media focus on this pandemic above any other story (Zhai Y et. al., 2020). The significant shortage of face masks and hand sanitizers does not help either (Ayittey, F.K. et. al., 2020). There is likely to be ongoing negative physiological consequences of chronic and ongoing stress. For instance, loneliness, which has increased under the COVID19 circumstances, appears to have a major negative impact on motivation and engagement with education and, as a result, increasing psychological distress and suffering in staff as well as students (Shoichet, C.E. 2020).

To put things in perspective, university students must confront a variety of unique and difficult challenges throughout and after this COVID-19 outbreak. The pandemic appears to be escalating and changing on a daily basis and so does the consequential challenge that it posed. Public health emergencies, such in this pandemic, generate fear and confusion and can lead to a wide range of psychological consequences, ranging from distress responses such as anxiety, depression, and substance abuse, to behavioural changes such as difficulty sleeping and stress over- or under-eating. (Zhai Y et. al., 2020; Liu, N., 2020) Emotional regulations may also be impaired with increasing experiences of anger and rage for some people. Before this COVID-19 pandemic began, it had been reported that one in five university students worldwide had experienced one or more diagnosable mental disorders (Auerbach, R.P. et. al., 2016). As we progress through these unprecedented times, the psychological impact of COVID-19 has the potential to dramatically increase this number and exacerbate mental health issues in students (Araújo, F.J.D.O. et. al., 2020).

As the number of positive cases and deaths steadily increasing all around the globe, it is understandable that students are psychologically affected too. Questions and worries arose; whether there are positive cases around their vicinity, whether they are safe in their current location, and whether they or their family are exposed to risk of contracting the infection (Cao, W. et. al., 2020). The dilemma is worse in those who have to be under quarantine, with the prospect of being infected being a very distressing thought for those involved. A study in 2004 of 129 Toronto residents who were under quarantine during the 2003 SARS epidemic found that $28.9 \%$ reported symptoms of post-traumatic stress disorder (PTSD) while $31.2 \%$ reported symptoms of depression (Robertson, E., et. al., 2004). It has been noted that longer durations of quarantine is associated with an increased prevalence of PTSD symptoms. For many people who may live alone, or have had to return to the family home to stay with family, the isolation from friends and peers can be incredibly challenging. 


\section{Lifestyle Changes and the "New Normal"}

As countries close educational institutions and restrict public movement, change in lifestyle is a certainty. The educational scene has changed too; with industrial training, clinical placements and rotations suspended for an unknown duration, students are left unsure of the future of their life and their studies (Mian, A. et. al., 2020; Liang, Z.C. et. al., 2020; Fuhat, N.S.A.M. et. al., 2020). For some students, the following of a strict schedule with timelines and deadlines, is what gives them motivation, purpose and drive, enabling them to focus on the tasks that need to get done and having a schedule rather than spending time alone with their internal psychological struggles. The sudden disruption of the daily life routine may result in increase in anxiety (Tang, B. et. al., 2020).

The distinct problem with social distancing and its correlation to mental health is the uncertain timeframe of when this might be all be over. Even if the university eventually opens, the 'new normal' would dictate smaller class gatherings, with social distancing applied on every circumstance. Lectures will be mostly online if possible, or face-to-face lectures or sessions are indicated, they will be done with minimal number of individuals and shorter durations. Large group discussions or numerous extra-curricular activities would not be encouraged. The graduation ceremony might even be less ceremonious, with likely less numbers of attendees allowed - or worst, postponed or cancelled (Lee, J. 2020; Abigail, J.H. 2020). Planning, or for some even thinking about, the future can cause higher experiences of fear and anxiety. The uncertainty of how the world will be post COVID-19 also adds to the sense of insecurity.

\section{Graduation and Employment Issues}

Looking to the future, the senior students of the university who are supposed to be graduating this year or next year would be worried that they would have to wait longer for their grand finale. This brings about cascades of implications, which may include economic stressors. Although an extension of the scholarship for eligible students may seems likely at sponsor's discretion, those who had to take study loans might not be so lucky. The loan made, mostly under Perbadanan Tabung Pendidikan Tabung Nasional (PTPTN) in Malaysian settings, would still have to be paid. With uncertainty clouding the future of their study, the delay in graduating will end up affecting their employment plans, which will eventually disrupt their capability to pay their dues. With this in mind, the Malaysian government has intervened and introduced a moratorium of PTPTN loans for 6 months (Kenneth, T. 2020). Nevertheless, the interest or the administrative charges of the loan will continue to pile up, making it harder for them to settle it, thus it is not all rosy for the students.

Having said that, the most unfortunate of all would be those who have had to rely on their parents for tuition fee and allowance? Because of the outbreak, some families would have lost their source of income, and the extension of the study would mean more money needed for the fees and the allowance. 
Few universities have taken the liberty to waive the tuition fee or give discounts for the next semester, but the allowances would still be managed by the families. This will cause further distress to the students and their families (Cao, W. et. al., 2020; Peng, L., et. al., 2020). From a wider perspective, the financial difficulties would affect the mental health, and subsequently poor mental health will exacerbate financial difficulty; a vicious cycle that needs attention from all stakeholders (Richardson, T. et. al., 2020).

Additionally, another implication that might be overlooked is the effect of delayed study completion on mental health itself. Although deterioration of mental health is well known to contribute to educational setback, it appears that delays in study completion also adversely affect mental health, specifically anxiety and depressive symptoms (Melkevik, O. et. al., 2020; Grøtan, K., et. al., 2020). Many students as well as their families have tentative life plans like when to graduate, when to start work, when to go for further studies, and many more (Cao, W. et. al., 2020). In view of this, disruption of these life plan, albeit unavoidable for the greater good in this case, may unfortunately precipitate anxiety or depression among those involved. On top of that, there will be severe disruptions of the prospect of employment in view of the impending global recession caused by the COVID-19 crisis. This will no doubt compound the anxiety and stress undergraduates are currently having (Sahu, P., 2020). In turn, this might lead to a 'domino effect', impairing academic performances or worse still, quitting studies altogether.

\section{Interventions for Mental Health of Undergraduates}

With all this recognized, it is imperative that the mental health of undergraduates are to be taken care of. This is in view of a study demonstrating 33.3\% prevalence of stress in a similar undergraduate population in 2017, 3 years prior to the pandemic, and it would stand to reason that the levels of stress would have been elevated due to the additive effects of the pandemic (Musiun, A., et. al., 2019). An ultra-brief psychological mindedness module, combining various therapeutic modalities like cognitive behavior threapy, mindfulnessbased therapies, and motivational interviewing techniques, was designed and adapted for COVID-19 purposes to deal with undergraduate mental health (Pang, N.T.P. et. al., 2020). An online system called COVIDCares was established in order to take referrals. This system incorporated peer support workers, using undergraduates to tend to each other's mental health, as it was felt that peers would understand the unique psychosocial matrix of issues better than non-peers. Qualitative feedback suggests that both first responders and users of the system were generally satisfied by the network.

Also, a wide-ranging mental health network was set up through the system, with telecounselling offered to university students via a wide network of counsellors, clinical psychologists, psychiatrists, and psychiatry medical officers. This network had been started even at the alert phase of the pandemic (Mukhsam, M.H., et. al., 2020). This allowed the catchment area to be much wider than merely passive case referrals.

A large-scale Depression, Anxiety and Stress survey was also performed, with students being responded to where indicated, as there needs to be a high index of suspicion 
of possible psychopathology (Salvaraji, L. et. al., 2020). This was also correlated with the evidence available, as a preliminary validation of the Fear of COVID-19 scale into Bahasa Malaysia in the same university student population suggested that fear of COVID-19 was related to all three constructs - depression, anxiety and stress (Pang, N.T., et. al., 2020).

\section{Conclusion}

Undergraduates face a multitude of challenges both from a mental health symptoms point of view, and due to the many psychological and social factors that contribute to uncertainty. This includes current quarantine prospects, future employment uncertainties, and the effect on delayed study completion. New norms have been adopted in inpatient and outpatient psychiatric settings (Sze, C.L., 2020), and it is instrumental that we focus on implementing similarly efficacious new norms in university settings. Multiple interventions have been performed to ensure that there is a wide-ranging mental health network covering as many students as possible through active case finding rather than passive case referrals, which is essential as interventions increase psychological mindedness and consequently reduce depressive symptoms (Pang, N.T.P. et. al., 2020). This hopefully will increase the levels of psychological wellness in vulnerable undergraduates.

\section{References}

Abigail, J.H. (2020). How the Class of 2020 Became the Class of COVID-19, CNBC, (2 April, 2020). https://www.cnbc.com/2020/04/02/how-the-class-of-2020-became-the-class-of-covid19.html

Araújo, F.J.D.O., Lima, L.S.A.D., Cidade, P.I.M., Nobre, C.B., Neto, M.L. (2020). Impact of SarsCov-2 and Its Reverberation in Global Higher Education and Mental Health, Psychiatry Res., 288, 112977(1-2). https://www.sciencedirect.com/science/article/abs/pii/S0165178120307009

Auerbach, R.P., Alonso, J., Axinn, W.G., Cuijpers, P., Ebert, D.D., Green, J.G., Hwang, I., Kessler, R.C., Liu, H., Mortier, P., Nock, M,K. (2016). Mental Disorders Among College Students in the World Health Organization World Mental Health Surveys. Psychol. Med., 46(14), 29552970. https:/www.cambridge.org/core/journals/psychological-medicine/article/mentaldisorders-among-college-students-in-the-world-health-organization-world-mental-healthsurveys/34942DEAFC35899349114B73E84FB080

Ayittey, F.K., Ayittey, M.K., Chiwero, N.B., Kamasah. J.S., Dzuvor, C. (2020). Economic impacts of Wuhan 2019-nCoV on China and the World. J. Med. Virol., 92(5), 473-475. https://onlinelibrary.wiley.com/doi/full/10.1002/jmv.25706

Cao, W., Fang, Z., Hou, G., Han, M., Xu, X., Dong, J., Zheng, J. (2020). The Psychological Impact of the COVID-19 Epidemic on College Students in China, Psychiatry Res., 287, 112934(1-5). https://www.sciencedirect.com/science/article/abs/pii/S0165178120305400

Fuhat, N.S.A.M. (2020). COVID-19: Bermulanya Era Latihan Amali Maya. Bernama. (27 April 2020). https://www.bernama.com/bm/am/news_covid-19.php?id=1836076

Greenberg, N., Docherty, M., Gnanapragasam, S., Wessely, S. (2020). Managing Mental Health Challenges Faced by Healthcare Workers During COVID-19 Pandemic. BMJ. 368, m1211(14). https://www.bmj.com/content/368/bmj.m1211

Grøtan, K., Sund, E.R., Bjerkeset, O. (2019). Mental Health, Academic Self-Efficacy and Study Progress Among College Students - The SHoT Study, Norway, Front. Psychol., 10, 45(1-11). https://www.frontiersin.org/articles/10.3389/fpsyg.2019.00045/full

Kang, L., Li, Y., Hu, S., Chen, M., Yang, C., Yang, B.X., Wang, Y., Hu, J., Lai, J., Ma, X., Chen, J., Guan, L., Wang, G., Ma, H., Liu, Z. (2020). The Mental Health of Medical Workers in 
Wuhan, China Dealing with the 2019 Novel Coronavirus. Lancet Psychiatry. 7(3), e14. https://www.thelancet.com/journals/lanpsy/article/PIIS2215-0366(20)30047-X/fulltext

Kenneth, T. (2020). COVID-19: PM announces Six-Month Grace Period for PTPTN Repayment, Malay Mail, (23 March, 2020). https://www.malaymail.com/news/malaysia/2020/03/23/covid19-ptptn-repayment-now-extended-to-six-months-grace-period-pm-announc/1849248

Koh E.B.Y., Pang N.T.P., Shoesmith W.D., James S, Nor H.N.M., Loo J.L. (2020). The behavior changes in response to COVID-19 pandemic within Malaysia. Malays. J. Med. Sci. 27(2), 4550. http://www.mjms.usm.my/MJMS27022020/05MJMS27022020_OA.pdf

Lee, J. (2020). Mental health effects of school closures during COVID-19. Lancet Child Adolesc. Health, 4(6), P421. https://www.thelancet.com/journals/lanchi/article/PIS23524642(20)30109-7/fulltext

Liang, Z.C., Ooi, S.B., Wang, W. (2020). Pandemics and their Impact on Medical Training: Lessons from Singapore. Acad. Med., 95(9):1359-1361.

https://journals.1ww.com/academicmedicine/Fulltext/2020/09000/Pandemics_and_Their_Impa ct_on_Medical_Training_.39.aspx

Liu, N., Zhang, F., Wei, C., Jia, Y., Shang, Z., Sun, L., Wu, L., Sun, Z., Zhou, Y., Wang, Y., Liu, W. (2020). Prevalence and Predictors of PTSS during COVID-19 Outbreak in China Hardest-Hit Areas: Gender Differences Matter. Psychiatry Res. 287, 112921(1-7). https://www.sciencedirect.com/science/article/abs/pii/S016517812030545X?via\%3Dihub

Melkevik, O., Hauge, L.J., Bendtsen, P., Reneflot, A., Mykletun, A., Aarø, L.E., (2016) Associations Between Delayed Completion of High School and Educational Attainment and Symptom Levels of Anxiety and Depression in Adulthood. BMC Psychiatry,16(1), 64(1-7). https://bmcpsychiatry.biomedcentral.com/articles/10.1186/s12888-016-0765-1

Mian, A., Khan, S. (2020). Medical Education during Pandemics: A UK Perspective. BMC Med., 18(1), 1-2. https://bmcmedicine.biomedcentral.com/articles/10.1186/s12916-020-01577-y

Mukhsam, M.H., Jeffree, M.S., Pang, N.T., Rahim, S.S., Omar, A., Abdullah, M.S., Lukman, K.A., Giloi, N., Salvaraji, L., Karim M.R.A., Saupin, S. Tat, Y.B., Hayati, M.F.M., Ibrahim, M.Y. Muhamad, A., Zainudin, S.P. (2020). A University-Wide Preparedness Effort in the Alert Phase of COVID-19 Incorporating Community Mental Health and Task-Shifting Strategies: Experience from a Bornean Institute of Higher Learning. Am. J. Trop. Med. Hyg., 103(3), 1201-1203. http://www.ajtmh.org/content/journals/10.4269/ajtmh.20-0458

Musiun, A., Lukman, K.A., Jeffree, M.S., Robinson, F., Hassan, M.R., Ghazi, H.F., Al-abed, A.A., Tha, N.O., Shamsudin, S.B. (2019). Prevalence of Stress and Its Associated Factors Among Medical Students in Sabah, Malaysia Borneo, Malaysian J. Public Health Med., 19(2), 116125. http://mjphm.org/index.php/mjphm/article/view/179/40

Pang, N.T., Kamu, A., Hambali, N.L., Mun, H.C., Kassim, M.A., Mohamed, N.H., Ayu, F., Rahim, S.S., Omar, A., Jeffree, M.S. (2020). Malay Version of the Fear of COVID-19 Scale: Validity and Reliability. Int. J. Ment. Health Addict., 3 July 2020, 1-10. https://dx.doi.org/10.1007\%2Fs11469-020-00355-4

Pang, N.T.P., Masiran, R., Tan, K.A., Kassim, A. (2020). Psychological Mindedness as a Mediator in the Relationship between Dysfunctional Coping Styles and Depressive Symptoms in Caregivers of Children with Autism Spectrum Disorder, Perspect. Psychiatr. Care. 56(3), 649656. https://doi.org/10.1111/ppc.12481

Pang, N.T.P., Shoesmith, W.D., James, S., Nor, H.N.M., Koh, E.B.Y., Loo, J.L. (2020). Ultra-Brief Psychological Interventions for COVID-19 Pandemic: Introduction of a Locally-Adapted Brief Intervention for Mental Health and Psychosocial Support Service. Malays. J. Med. Sci., 27(2), 51-56. http://www.mjms.usm.my/MJMS27022020/06MJMS27022020_OA.pdf

Peng, L., Zhang, J., Li, M., Li, P., Zhang, Y., Zuo, X., Miao, Y, Xu, Y. (2012). Negative Life Events and Mental Health of Chinese Medical Students: The Effect of Resilience, Personality and Social Support. Psychiatry Res., 196(1), 138-141.

https://www.sciencedirect.com/science/article/abs/pii/S0165178111007906?via\%3Dihub 
Richardson, T., Elliott, P., Waller, G., Bell, L. (2015). Longitudinal Relationships between Financial Difficulties and Eating Attitudes in Undergraduate Students, Int. J. Eat. Disord., 48(5), 517521. https://onlinelibrary.wiley.com/resolve/doi?DOI=10.1002/eat.22392

Robertson, E., Hershenfield, K., Grace, S.L., Stewart, D.E. (2004). The psychosocial effects of being quarantined following exposure to SARS: A Qualitative Study of Toronto Health Care Workers. Can. J. Psychiatry., 49(6), 403-407. https://journals.sagepub.com/doi/10.1177/070674370404900612

Sahu, P. (2020). Closure of Universities Due to Coronavirus Disease 2019 (COVID-19): Impact on Education and Mental Health of Students and Academic Staff. Cureus, 12(4), e7541(1-6). https://www.cureus.com/articles/30110-closure-of-universities-due-to-coronavirus-disease2019-covid-19-impact-on-education-and-mental-health-of-students-and-academic-staff

Salvaraji, L., Rahim, S.S., Jeffree, M.S., Omar, A., Pang, N.T., Ahmedy, F., Hayati, F., Yeap, B.T., Giloi, N., Saupin, S., Muhammad, A. (2020). The Importance of High Index of Suspicion and Immediate Containment of Suspected COVID-19 Cases in Institute of Higher Education Sabah, Malaysia Borneo, Malaysian J. Public Health Med., 20(2), 74-83. http://mjphm.org/index.php/mjphm/article/view/573/184

Shoichet, C.E. (2020). Why the Impact of Coronavirus Could be Particularly Bad on College Campuses CNN: Cable News Network [March 13, 2020]. https:/edition.cnn.com/2020/03/07/health/universities-coronavirus-impact/index.html

Sze, C.L., Chun, K.N., Kassim, M.A., Pang, N.T. (2020). Unique Challenges for Mental Health in Inpatient Settings Amid the COVID-19 Pandemic: Perspective from Sabah, Borneo Epidemiology Journal, 1(1), 79-87. https://jurcon.ums.edu.my/ojums/index.php/bej/article/view/2439

Tang, B., Bragazzi, N.L., Li, Q., Tang, S., Xiao, Y., Wu, J. (2020). An Updated Estimation of the Risk of Transmission of the Novel Coronavirus (2019-nCov), Infect. Dis. Model. 5, 248-255. https://www.sciencedirect.com/science/article/pii/S246804272030004X

UNESCO-IIEP, COVID-19 Educational Disruption and Response (2020) [24 November 2020]. http://www.iiep.unesco.org/en/covid-19-educational-disruption-and-response-13363

Van, L.W.; Parolin, Z. (2020). COVID-19, School closures, and child poverty: A social crisis in the making. Lancet Public Health, 5(5), E243-E244. https://www.thelancet.com/journals/lanpub/article/PIIS2468-2667(20)30084-0/fulltext

Zhai Y, Du X. (2020). Addressing Collegiate Mental Health Amid COVID-19 Pandemic. Psychiatry Res. 288, 113003(1-2).

https://www.sciencedirect.com/science/article/abs/pii/S0165178120308398 